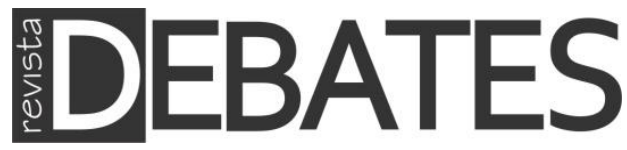

\title{
A eleição de Jair Bolsonaro: A construção do medo e ódio na campanha eleitoral de 2018
}

\author{
Jair Bolsonaro's election: Building fear and hate in the 2018 election \\ campaign
}

\section{Deysi Cioccari \\ Vanderlei Ezequiel \\ Romer Mottinha}

\section{Resumo}

Este trabalho analisa as eleiçóes de 2018 e a construção social dos discursos de ódio e medo durante o pleito. Tendo como protagonista o presidente eleito Jair Bolsonaro, o período eleitoral contou com narrativas dramáticas. O corpus deste trabalho é especificamente o período eleitoral, tendo como ápice o ataque sofrido pelo então candidato no dia 6 de setembro de 2018 e seus desdobramentos no campo político. O referencial teórico baseia-se em Zygmunt Bauman (2007), Christopher Lasch (1983,1986) e Thomas Hobbes $(1966,1998)$ para analisar o medo, e em Jeremy Waldron e Ronald Dworkin para entendermos o ódio na política brasileira. Concluiu-se que ódio e medo foram primordiais na eleição do candidato vencedor.

\section{Palavras-chave}

Comunicação; Política; Medo; Discurso do Ódio.

\section{Abstract}

This paper analyzes the 2018 Brazilian elections and the social construction of hate and fear speeches during the election. With the protagonism of the elected President Jair Bolsonaro, the election period featured dramatic narratives. The corpus of this work is specifically the electoral period, having as its peak the attack suffered by the, then candidate, Jair Bolsonaro on September 6, 2018 and its developments in the political field. Our theoretical framework draws on Zygmunt Bauman, Christopher Lasch and Thomas Hobbes to analyze fear, and Jeremy Waldron and Ronald Dworkin for understanding hatred in Brazilian politics. It was concluded that hatred and fear were paramount in the election of the winning candidate.

\section{Keywords}

Communication; Politics; Fear; Hate Speech. 


\section{Introdução}

Jair Bolsonaro foi parlamentar por 27 anos no Congresso Nacional. A campanha de primeiro turno do atual presidente quebrou quase todas as regras de marketing político quando ele utilizou imagens não fabricadas, abriu mão de um marqueteiro e abusou da informalidade ${ }^{1}$. (É bom ponderar que houve, sim, uma estrutura profissional na campanha, mesmo que os filhos - em especial, o "02" tenham interferido diretamente nas estratégias de marketing e comunicação). Uma solidez no eleitorado havia sido alcançada, mas o atentado sofrido em 6 de setembro de 2018 deu outros contornos à campanha eleitoral . A polarização e o discurso do "nós" contra "eles" foi acirrada, sendo complementada com um discurso de ódio, e com o medo tomando a narrativa do pleito eleitoral com contornos espetaculares.

Bordieu (1997, p. 25) afirma que a televisão convida à "dramatização" ao colocar em cena imagens e exagerar a importância. Bucci (2004, p. 143-144) ressalta o paradigma estabelecido pelo Jornal Nacional da Rede Globo pela tendência em encerrar cada edição diária do programa com alguma história edificante, como se fosse um "final feliz", por causa da influência da estrutura de narrativa melodramática das novelas, que formaram o hábito da audiência televisiva no Brasil. Para o pesquisador, o telejornalismo não escapa da "teatralização do relato factual" e complementa que a grande maioria dos programas não prima pela separação entre opinião e relato factual, como é visto nos jornais impressos, sendo assim, muito raramente o telespectador é convidado a ouvir a leitura de um editorial de forma clara e direta.

A prática jornalística nunca dependeu tanto da reflexão e do estudo como agora. Uma redação não é um balcão onde notícias são empacotadas. Uma redação é um núcleo encarregado de pensar. Ela é tanto melhor quanto melhor for a sua capacidade de elaboração coletiva. A qualidade do que ela apura, escreve, narra, edita, fotografa e desenha é consequência do modo como ela pensa - ou do modo como ela não pensa. Jornalistas não são "mineradores" de informação exclusiva que ocasionalmente são instados a pensar, mas precisam ser pensadores com grande capacidade executiva. O jornalismo é uma atividade intelectual - ou é inconsequente e tolo (BUCCI, 2004, p. 199).

\footnotetext{
${ }^{1} \mathrm{O}$ então candidato abriu mão de marqueteiros durante o pleito eleitoral, mas manteve uma estrutura profissional que o apoiou, chefiada pelo ex-ministro Gustavo Bebbiano.
} 
A história do então candidato, Jair Bolsonaro, obedeceu a essa narrativa que a imprensa tanto privilegia. O discurso do "nós contra eles", aliado ao atentado contra o candidato trouxe uma nova tonalidade à campanha: o medo, amplificado pela imprensa, pelas redes sociais e pelos discursos dos candidatos; o medo que, para Bauman (2007), é um objeto de estudo sociológico, pois é fabricado, inculcado, construído e instalado no sujeito. A questáo do medo penetra a realidade social na medida em que o Estado deixa de ser, num dado momento do século $\mathrm{XX}$, o garantidor da segurança social, da existência digna e passa a permitir que serviços de proteção individual ganhem espaço. Nesse contexto, o discurso do ódio foi potencializado. De modo geral, o discurso de ódio - tradução do termo em inglês: hate speech - é aquele discurso que promove o ódio e incita a discriminação, hostilidade e violência. Refere-se a qualquer ato de comunicação que diminua, inferiorize uma pessoa, empregando aspectos passíveis de discriminação tais como: gênero, raça, religião, nacionalidade, orientação sexual, entre outros. Assim como qualquer expressão discursiva, o discurso de ódio exige a concretização das ideias, isto é, sair do plano mental para o plano fático.

O objetivo deste trabalho é analisar a tônica do medo e do ódio na campanha eleitoral de 2018. Nosso corpus é especificamente o atentado à faca sofrido pelo entáo candidato em 6 de setembro de 2018 e seus desdobramentos. Nosso referencial teórico baseia-se em Zygmunt Bauman e Christopher Lasch para analisar o medo e em Jeremy Waldron e Ronald Dworkin para entendermos o ódio na política brasileira. Também utilizamos Thomas Hobbes para embasamento.

\section{O discurso de ódio}

Sem liberdade de expressão não há democracia. Ela ocupa o centro de uma estrutura democrática (GARGARELLA, 2011, p. 30) e, por isso, no Brasil, foi inscrita topograficamente em posição de destaque na Constituição Federal (art. 5o, IX). Em uma democracia, no entanto, buscando-se o manto da proteção da própria liberdade de expressão, podem ocorrer manifestaçóes de intolerância e discriminação contra grupos vulneráveis, como negros, indígenas, homossexuais, mulheres e minorias religiosas.

Samanta Ribeiro Meyer-Pflug (2009, p. 97) define o discurso de ódio como a manifestação de "[...] ideias que incitem a discriminação racial, social ou religiosa em determinados grupos, na maioria das vezes, as minorias”. Alvaro Paul Diaz (2011, p. 
575) destaca que o discurso do ódio deve ser mais que uma manifestação de antipatia, deve indicar a hostilidade contra determinado grupo. É importante, nesse caminho, destacar a necessidade de analisar os elementos de discriminação e externalidade do discurso do ódio, bem como seu caráter segregacionista (SILVA, 2011) e visualizar a posição dos que protagonizam o fenômeno.

Em sua análise sobre o hate speech nos julgados emblemáticos realizados pela Suprema Corte estadunidense, Daniel Sarmento (2006, p. 60) destaca que as limitaçóes no campo da liberdade de expressão somente ocorrem se há incitação para a prática de atos violentos, o que aponta para uma concepção muito formal da liberdade, a qual ignora a força silenciadora que o discurso opressivo dos intolerantes pode provocar sobre os seus alvos (SARMENTO, 2006, p. 63).

O discurso de ódio está dirigido a estigmatizar, escolher e marcar um inimigo, manter ou alterar um estado de coisas, baseando-se numa segregação. Para isso, entoa uma fala articulada, sedutora para um determinado grupo, que articula meios de opressão. Os que não se enquadram no modelo dominante de "[...] sujeito social nada abstrato: masculino, europeu, cristão, heterossexual, burguês e proprietário" (RIOS, 2008, p. 82) são os potenciais inimigos.

No período da ditadura militar no Brasil, a censura recaía quase sempre sobre manifestaçôes expressivas que o governo considerava perigosas ou ofensivas aos seus próprios interesses. Atualmente, após a redemocratização e constitucionalização do país, problemas desta natureza não aparecem mais, ou, quando surgem, são prontamente equacionados pelos tribunais. A Constituição de 1988 protegeu enfaticamente a liberdade de expressão, e o Judiciário desfruta da independência que lhe faltava algumas décadas atrás para fazer valer esta garantia contra eventuais desvios autoritários dos governantes. A imprensa hoje trabalha com liberdade, salvo algumas exceçóes, como quando o ex-presidente Lula, num rompante autoritário expulsou do país (RILA; KRIEGER, 2004) o jornalista Larry Rother, correspondente do New York Times, porque numa matéria criticara os seus supostos excessos etílicos. Contudo, o Superior Tribunal de Justiça concedeu liminar suspendendo imediatamente o ato, e o próprio Governo, duramente criticado pela opinião pública, acabou voltando atrás e não recorreu contra a citada decisão.

Hoje a liberdade de expressão está num cenário mais complexo, em que todos têm voz e o Governo é menos autoritário. Porém, a questão da liberdade de expressão envolve o manejo de valores extremamente importantes numa sociedade, como liberdade e tolerância. Mas até que ponto tudo deve ser dito? 
Uns, de um lado, afirmam que a liberdade de expressão não deve proteger apenas a difusão das ideias com as quais simpatizamos, mas também aquelas que nós desprezamos ou odiamos, como o racismo. Para estes, o remédio contra más ideias deve ser a divulgação de boas ideias e a promoção do debate, não a censura. Do outro lado, estão aqueles que sustentam que as manifestações de intolerância não devem ser admitidas, porque violam princípios fundamentais da convivência social como os da igualdade e da dignidade humana, e atingem direitos fundamentais das vítimas. $\mathrm{O}$ hate speech já foi condenado no Brasil pelo Supremo Tribunal Federal, em 2003, no caso Ellwanger ${ }^{2}$. Decidiu-se, naquele julgamento, que a liberdade de expressão não protege manifestaçóes de cunho antissemita, que podem ser objeto de persecução penal pela prática do crime de racismo.

A ideia básica da liberdade de expressão como instrumento para a obtenção da verdade parte da premissa de que, no contexto do debate livre entre pontos de vista divergentes sobre temas polêmicos, as melhores ideias prevalecerão. Sob esta perspectiva, a liberdade de expressão é vista não como um fim em si, mas como um meio para a obtenção das respostas mais adequadas para os problemas que afligem a sociedade.

Stuart Mill (1978), no capítulo II da sua obra On Liberty ${ }^{3}$, defende que proibir a divulgação de determinados pontos de vista porque eles hoje são considerados equivocados pelo governo ou mesmo pela maioria da populaçáo seria um grande erro, pois é provável que a ideia em questão esteja certa, ou que tenha pelo menos algum resquício de correção e, assim, a sua supressão privaria a sociedade do acesso a algo verdadeiro.

Para Mill (1978), ainda que uma ideia seja completamente incorreta, proibir a sua expressão pública continuaria sendo um grave equívoco. Isso porque o confronto que se estabelece entre os diferentes pontos de vista é sempre benéfico para a sociedade, na medida em que permite que as ideias certas se fortaleçam na discussão. Um outro ponto a ser pensado é que, ao invés de uma discussão voltada para o bem comum, corre-se o risco de deflagração de uma verdadeira guerra no espaço público, em que a política seria reduzida ao modelo de Carl Schmitt (1992), de batalha entre inimigos, que é tudo menos democrático.

\footnotetext{
${ }^{2}$ HC no 82.424/RS, Plenário, Rel. Min. Maurício Corrêa, julgamento concluído em 19 de setembro de 2003.

${ }^{3} \mathrm{O}$ livro foi publicado pela primeira vez em 1859 . Consultamos neste estudo a ediçáo publicada em 1978.
} 
94 | Deysi Cioccari, Vanderlei Ezequiel e Romer Mottinha

Dworkin entende que a liberdade de expressão é um direito universal e irrestrito (ou quase irrestrito), sendo parte constitutiva da democracia. Assim, o princípio básico que dá suporte à liberdade de expressão como um direito humano universal é a exigência de que todos devem ser tratados com igual consideração e respeito, ou seja, a aceitação da condição da dignidade humana (cf. DWORKIN, 2009, p. vi-vii).

Embora os processos majoritários sejam condição necessária à legitimidade política, uma democracia justa, segundo Dworkin (2009), deve ter o que ele denomina de democratic background. Dessa forma, a decisão da maioria somente será justa quando todos tenham oportunidade de expressar suas opiniōes, medos ou gostos, ou mesmo preconceitos. $\mathrm{O}$ autor entende que, ao estabelecer restriçóes à liberdade de expressão, como vedações aos discursos de ódio, o Estado deixaria de respeitar o status de cada indivíduo como membro livre e igual da comunidade política (cf. DWORKIN, 2009, p. vii).

Para Dworkin (2009), dizer que um indivíduo tem direito significa dizer que esse indivíduo pode fazê-lo mesmo que isso seja errado, independentemente de o exercício contribuir a um objetivo não individualizado.

Já Jeremy Waldron defende que alguma restrição aos discursos de ódio é necessária justamente para assegurar que a intolerância não solape os princípios e valores democráticos. Essa posição é mais próxima à adotada na Europa e no Brasil.

[...] incitam o 'ódio contra qualquer grupo identificável em que tal incitação é suscetível de conduzir a uma violação da paz social' (Canadá); 'ou declaraçốes pelas quais um grupo de pessoas é ameaçado, ridicularizado ou degradado em razão de sua raça, cor da pele, nacionalidade ou etnia' (Dinamarca); ou ataques à 'dignidade humana de outros por insultar, difamar maliciosamente ou difamar segmentos da população' (Alemanha); ou 'palavras ameaçadoras, abusivas ou insultantes [...] que possam excitar hostilidade contra ou reduzir à ignomínia qualquer grupo de pessoas [...] com fundamento na cor, na raça ou étnica, ou em origens étnicas ou nacionais de um grupo de pessoas' (Nova Zelândia); ou o uso de 'palavras ameaçadoras, abusivas ou insultantes ou comportamentos,' quando destinam--se a incitar ódio racial,' ou quando 'considerando todas as circunstâncias o ódio racial é capaz de causar agitaçóes desse modo' (Reino Unido) (WALDRON, 2012, p. 8). 
Há dois argumentos importantes na discussão levantada por Waldron (2012) a respeito dos discursos de ódio: primeiramente, ele sustenta que os discursos de ódio afetam a dignidade dos indivíduos; em segundo lugar, afirma que tais discursos comprometem e corrompem o ambiente democrático das sociedades. A análise da argumentação de Waldron é feita a partir de dois aspectos. Primeiramente, será abordada a sua diferenciação entre discursos que afetam a dignidade ou a reputação dos indivíduos e discursos que meramente ofendem e, em segundo lugar, sua avaliação da premissa da legitimidade democrática de Dworkin (2009). Interessa-lhe principalmente a parte deste conceito que sustenta que, em uma sociedade bem ordenada, todos aceitam e sabem que todos os demais aceitam os mesmos princípios de justiça (WALDRON, 2012, p. 69). Sua principal indagação é: "como uma sociedade bem-ordenada parece na prática?” Discursos de ódio devem ser tolerados pela lei em uma sociedade bem-ordenada? A princípio, “[...] uma sociedade não pode ser bem-ordenada se pessoas defendem o ódio racial ou religioso, haja vista a ideia de uma sociedade bem-ordenada ser aquela amplamente e efetivamente governada por uma concepção de justiça”" (WALDRON, 2012, p. 77-78). Em outras palavras, “[...] uma sociedade não pode ser bem ordenada a menos que os intolerantes e racistas desistam de sua missão e aceitem os princípios básicos de justiça e de igual respeito aos quais tinham aversão" (WALDRON, 2012, p. 78).

\section{O medo}

Perdeu-se a confiança no futuro (LASCH, 1986, p. 9). A construção social do medo se dá em uma sociedade individualista que busca sobreviver por não acreditar no futuro.

A vida líquida flui ou se arrasta de um desafio para outro e de um episódio para outro, e o hábito comum dos desafios e episódios é sua tendência a terem vida curta. Pode-se presumir o mesmo em relação à expectativa de vida dos medos que atualmente afligem as nossas esperanças. Além disso, muitos medos entram em nossa vida juntamente com os remédios sobre os quais muitas vezes você ouviu falar antes de ser atemorizado pelos males que esses prometem remediar (BAUMAN, 2007, p. 14).

Cada autor tem uma linha de pensamento para tentar explicar a insegurança que vivemos. Para Lasch (1986, p. 9), o ponto é que o desencanto gera a necessidade 
de sobreviver a qualquer custo. "O risco de desintegração individual estimula um sentido de individualidade que não é 'soberano' ou 'narcisista', mas simplesmente sitiado”. Esta mentalidade sitiada, por vezes, possui características comuns, como a ironia defensiva, a falta de compromisso emocional, o sentimento de impotência e sacrifício, o deslumbramento por situaçóes extremas e a possibilidade de uso destas liçôes no dia a dia da pessoa. O cotidiano passa a ser conduzido pelas estratégias de sobrevivência, descompromisso emocional em relaçáo aos outros e abdicação do passado e do presente com a meta de viver um dia por vez. Uma autogestão dentro de uma sociedade burocrática que leva a um sistema de total controle e cujo valor cultural é solidificado na falta de diferenciação do "eu" perante o universo exterior.

A cultura do narcisismo é o desbotamento da concepção de um mundo durável, comum e público, que aumenta o temor pela separação e, em paralelo, retira as forças dos recursos psicológicos que tornam possível enfrentar o medo de forma realista. Tal situação deu liberdade ao pensamento de constrangimentos externos e expôs as angústias internas.

Os fatos inelutáveis da separação e da morte somente são suportáveis porque o mundo tranquilizador dos objetos fabricados pelo homem e da cultura humana restaura o sentido de vinculação original em uma nova base. Quando esse mundo começa a perder a sua realidade, o medo da separação torna-se quase esmagador e a necessidade de ilusôes passa a ser, consequentemente, mais intensa que nunca (LASCH, 1986, p. 178).

Bauman questiona o fato de essa transformação social poder ter gerado a perda do controle sobre o mundo social. Para o autor, as oscilaçóes da vida atual aparecem em comum com "a fragilidade dos vínculos humanos" (2007, p. 64) como origem do problema, atributo provavelmente definidor desta vida líquido-moderna. Ao voltar para si próprio, o homem estabeleceu uma sociedade com uma dolorosa consciência da tensão entre as aspiraçóes ilimitadas e a compreensão limitada, entre as sugestôes originais de imortalidade e o estado cativo, entre a unidade e a separação (LASCH, 1986, p. 13-14). 
O medo é mais assustador quando difuso, disperso, indistinto, desvinculado, desancorado, flutuante, sem endereço nem motivo claros; quando nos assombra sem que haja uma explicação visível, quando a ameaça que devemos temer pode ser vislumbrada em toda parte, mas em lugar algum se pode vê-la. "Medo" é o nome que damos a nossa incerteza: nossa ignorância da ameaça e do que deve ser feito - do que pode e do que não pode - para fazê-la parar ou enfrentá-la, se cessá-la estiver além do nosso alcance (BAUMAN, 2007, p. 8).

A existência de uma espécie de uma segunda camada de medo com um fundo social entre os seres humanos é denominada por Bauman (2007) como o "medo derivado", uma sensação que orienta o indivíduo até mesmo em uma situação que não haja o risco de ameaça iminente.

\section{O atentado contra o então candidato Jair Bolsonaro}

No dia 6 de setembro de 2018, o então candidato à presidência da República, Jair Bolsonaro, sofreu um atentado à faca em Juiz de Fora, MG. Ele era carregado nos ombros por apoiadores quando um homem se aproximou e o feriu com uma faca na barriga. $\mathrm{O}$ agressor, Adélio Bispo de Oliveira, de 40 anos, foi preso em flagrante e confessou o crime. Ainda no mesmo dia a Polícia Federal (PF) abriu inquérito para investigar o caso. Bolsonaro foi levado à Santa Casa de Misericórdia de Juiz de Fora. O então candidato foi levado à Unidade de Terapia Intensiva (UTI) da Santa Casa do município. Os presidenciáveis cancelaram suas agendas de 7 de setembro após o atentado.

Dono de um discurso agressivo, Bolsonaro provoca polarizaçóes desde quando deputado federal. Durante a campanha eleitoral, mesmo antes do atentado, Bolsonaro usou como simbologia à apologia às armas. Em entrevista à Revista Playboy, em 2011, disse "[...] prefiro que um filho meu morra num acidente do que apareça com um bigodudo por aí”.

Em 2008, Bolsonaro disse que o índio Jacinaldo Barbosa, após atirar-lhe um copo de água durante audiência pública para discutir a demarcação da reserva Raposa/Serra do Sol, "[...] deveria comer capim ali fora para manter as suas origens" ${ }^{4}$. E, em 2016, afirmou que "[...] não empregaria [homens e mulheres] com o mesmo

4 Disponível em: <https://blogdosakamoto.blogosfera.uol.com.br/2018/12/17/raposa-serra-do-solbolsonaro-mandou-indio-comer-capim-em-debate-de-2008/>. Acesso em: 12 julho 2019. 
salário. Mas tem muita mulher que é competente", em entrevista ao programa Superpop, da RedeTV (2014).

Em 1999, durante solenidade no Clube da Aeronáutica, disse que, pelo o crime que estava cometendo contra o país, Fernando Henrique Cardoso "merecia o fuzilamento", e repetiu a afirmação em pelo menos dois programas de TV.

Como qualquer expressão discursiva, o discurso de ódio exige a concretização das ideias, isto é, sair do plano mental para o plano fático. Quando náo é externado, o discurso é apenas pensamento, emoção, não causando qualquer dano a quem porventura seja alvo. O problema surge quando o pensamento é externado, cedendo lugar à presença da palavra. Concretizado, o discurso realiza seus efeitos nocivos, destacando: ataque à dignidade alheia e violaçóes a direitos fundamentais. Em suma, manifestado publicamente, o discurso de ódio causa o dano.

O discurso de ódio também pode ser dividido em dois atos: o insulto e a instigação. O primeiro refere-se diretamente à vítima, ou seja, a agressão a uma pessoa ou grupo de pessoas que partilham de determinado traço. Enquanto o segundo ato direciona-se a terceiros, não identificados com as vítimas, que são convocados para reforçar o grupo dos agressores, não apenas no discurso, mas também com ações.

Jair Bolsonaro já vinha proferindo seus discursos raivosos direcionados às minorias. Na campanha, o ápice da violência e do modus operandi "nós contra eles" deu-se no atentado. As imagens repercutidas incessantemente pela imprensa nos dias que se seguiram suscitaram uma série de debates sobre a validade do discurso extremista, da propagação da violência e deram o tom ao surgimento de ponderações mais claras. Após o atentado, o filho vereador do candidato, Carlos Bolsonaro, tornou-se o pitbull da campanha.

Às vésperas do segundo turno, um vídeo em que Eduardo Bolsonaro aparecia defendendo o fechamento do Supremo Tribunal Federal (STF) "por um cabo e um soldado" obrigou Bolsonaro a enviar carta de desculpas ao Supremo, por meio do decano da Corte, ministro Celso de Mello. A família também estava envolvida pelos extremismos.

No final de setembro, Carlos Bolsonaro postou uma foto em que um homem aparecia com o rosto encoberto por um saco plástico ensanguentado. Ele foi acusado de apologia à tortura. Mas negou, informando que era uma ironia e crítica aos adversários do pai - que haviam divulgado antes a imagem. Há sete anos, o vereador foi alvo de ação do Ministério Público por ter tuitado um texto considerado homofóbico.

A Bancada da Bala sempre foi um dos respaldos de Jair Bolsonaro, que 
fortaleceu seu discurso respaldado por uma grande maioria conservadora do Congresso Nacional.

Bolsonaro utiliza o discurso do medo para respaldar-se num país em que há a construção de um imaginário no qual o delinquente é sempre um "outro" distante do "cidadão de bem" e que obstrui o bom andamento da sociedade. Os aspectos identitários da vida policial como a valorização das tradiçôes, da moralidade cristã e a espetacularização dos embates são transpostos para a vida política como forma de justificativa da proteção desses "cidadãos de bem", o que aponta para uma cidadania cindida pela desigualdade abertamente admitida entre aqueles que merecem usufruir de seus direitos - em especial, o direito à vida - e aqueles que abandonaram o direito à cidadania para entrar no crime (CIOCCARI e PERSICHETTI, 2018a, p. 206).

Numa amostra de imagens selecionadas para esta pesquisa, identificamos a construção da imagem de Bolsonaro sempre coerente com seu discurso agressivo. As imagens de Bolsonaro nos veículos $\mathrm{O}$ Estado de S. Paulo e Folha de S. Paulo são sempre com referências ao porte de armas, dedo em riste e reforçando seu militarismo (CIOCCARI, 2018). Em 6 de setembro, dia do atentado, o jornal Folha de S. Paulo replica esta imagem em sua capa.

Figura 1 - Bolsonaro chuta boneco do ex-presidente Lula durante evento em Ceilândia (DF)



Fonte: Teixeira e Daniel (2018). 
Partamos da premissa de que Hobbes estava certo quando dizia que do medo nasce o político (isto é, a ação política) e do pacto nasce a política, isto é, o imperativo da obediência a um soberano legitimado pelo consentimento: a origem das sociedades deve ser reputada pelo medo recíproco (a mutuo metu) entre os homens e não, como se costuma pensar, pela boa vontade recíproca (a mutua benevolentia). Assim, o medo é o que explica, para Hobbes (2003), como, segundo ele mesmo, não se costumava pensar até então a sociedade entre os homens. E mais: não somente os homens se associam por medo, como, uma vez associados - e para Hobbes, como se sabe, essa associação se faz por contrato -, é o medo que dá sustentação às relações contratuais em que consistem os vínculos civis. Pois, como se diz numa passagem igualmente bem conhecida do Leviatã, onde não houver o medo de um poder coercitivo capaz de constranger os homens ao cumprimento dos contratos, estes não são válidos.

Figura 2 - Bolsonaro é atacado a faca e operado de emergência; rivais condenam atentado

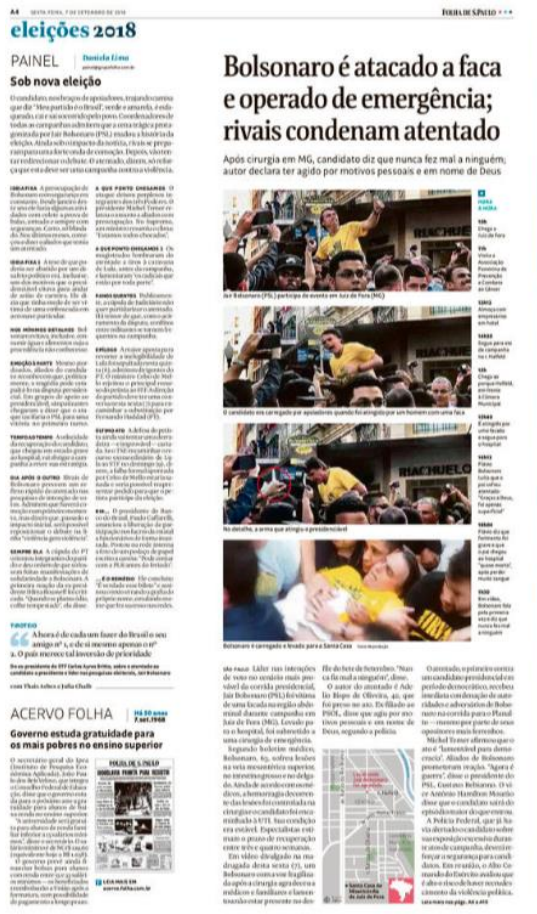

Fonte: Jaworski (2018). 
Hobbes (2003) afirma que, para uma sociedade prosperar, o estado soberano tem que se colocar acima do estado de tensão. A campanha de Jair Bolsonaro e, especificamente, seu atentado colocam a tensão no seu auge.

\section{Considerações finais}

A compreensão do discurso do ódio por si só não é completa, o que explica a dificuldade da construção de um padrão conceitual para o problema.

Partindo da premissa de que o indivíduo só se preocupa com as coisas que pode prever, pois é só delas que terá chance de lutar para escapar (BAUMAN, 2007, p. 18), é válido destacar que as matérias compreendidas como casos de violência urbana são aquelas que demonstram ao espectador a chance dele ou de um ente querido ficar suscetível a um perigo ou ameaça oriunda de desconhecidos e cujas causas não são naturais.

Os efeitos de um medo e de outro tampouco deixam de convergir. O medo dos poderes invisíveis quando cultivado em solo político reverte-se, como vimos, no poder visível de uma autoridade. Mas, além dos poderes invisíveis, os homens temem o poder dos outros homens. Segue-se que um poder mal fundado, um poder fundado sobre a simples opiniáo de um poder, como o das autoridades religiosas, é um poder temível e consequentemente sujeito à disputa, seja pelas armas da guerra e pela violência, seja pelas armas do discurso e da eloquência, influenciando a opiniáo que os homens fazem uns dos outros e, com isso, alterando as correlaçôes de poder, jamais estáveis enquanto estiverem à mercê do jogo das opinióes e das paixóes, do jogo das circunstâncias.

A comparação entre os homens é causa de disputa especialmente porque há uma necessidade natural segundo a qual cada um precisa ser melhor avaliado que o outro.

Contudo, essa avaliação não é importante exclusivamente por um viés de julgamento moral, mas porque ser considerado um homem honrado e digno significa que seu valor foi reconhecido por outros homens. E ter seu valor reconhecido é o mesmo que ter reconhecido seu poder, uma vez que o valor de um homem é seu preço.

Ao considerar o valor de um homem como algo relativo ao julgamento de outros homens, é possível compreender que, de acordo com Hobbes (1988), o convívio social é permeado por uma constante competição. Tal competição não se dá por um impulso vaidoso ou pela simples conquista da estima pública, mas 
principalmente pelo fato de que tal estima e consideração são sinônimos de poder. Como assinala Hobbes (1988), todo homem, por designação da natureza, tende a essa busca incessante por poder. Jair Bolsonaro precisa do embate para fortalecer a própria posição.

Jair Bolsonaro sempre teve em sua narrativa um discurso mais agressivo. Conforme mencionado nesse trabalho, é um representante ativo da Bancada da Bala, da Bancada Evangélica, afinal, conforme Ribeiro (2006), o poder mais forte não é necessariamente o da espada visível, o do gládio da justiça e da guerra, que o soberano (leigo) empunha - mas o de uma espada invisível, a da fé e da religiáo. Seu discurso e sua imagem antes do pleito eleitoral foram elaborados numa lógica conservadora. Seu próprio slogan de campanha reiterou isso: "Brasil acima de tudo, Deus acima de todos".

A exigência de ter reconhecida pelo outro a sua própria força, astúcia e inteligência faz com que os homens tenham como horizonte a expectativa de que o caminho para a satisfação de seus desejos pode ser bloqueado por outro homem. Bolsonaro viu em todos os outros concorrentes políticos os homens a serem bloqueados. Com a exposição da Operação Lava Jato da corrupção em outros partidos, os 27 anos de Congresso Nacional de Bolsonaro não lhe impediram a alcunha de "novo" na política, visto que, no país, o inimigo a ser bloqueado é a "velha política" e tudo o que ela representa. O medo da corrupção, a insegurança nas ruas, as pautas progressistas nunca discutidas reverberam numa parcela da população que elegeu o Congresso mais conservador pós-64. Essa mesma parcela da população já dava sinais de que o próximo presidente seria conservador. E foi Jair Bolsonaro. Que se aproveitou de uma sociedade desamparada e usou a tática do medo e desconfiança e elegeu-se presidente. Coerção, restrição, sujeição, medo e temor são algumas das principais características que podem ser legitimamente utilizadas pelo Estado para lidar com os conflitos. Se o inimigo não existe, cria-se. Hobbes (2003) ressaltou a guerra do todos contra todos, mas também lembrou que há monstro no poder do Estado.

Discursos de ódio não podem ser aceitos em nenhum modelo de sociedade moderna, principalmente numa democracia. As formas de expressão odiosas, intolerantes e retrógradas não são parte da escala de valores democráticos da sociedade ou do Estado. Discursos como os apontados neste trabalho, de natureza agressiva, são um dos riscos mais alarmantes para a democracia. O discurso do, então, deputado Jair Bolsonaro aqui analisado, além de expor o seu despreparo para lidar com situações de divergências ideológicas, também expõe o acirramento de posições políticas 
antagônicas na sociedade brasileira. O teor do discurso, mais do que uma discussão acalorada entre atores políticos de tendências opostas, reforça a ideia da vulnerabilidade feminina diante da imposição da força e agressividade masculina. Se, como afirma Hobbes (1969), o medo foi o produtor de racionalidade que permitiu a saída do homem da barbárie, a gênese e necessidade da racionalidade instrumental voltada para a dominação da natureza devem aparecer como reação ao sentimento do medo.

Deysi Cioccari é Doutora em Ciências Sociais pela PUC/SP. Atualmente é Pós-doutoranda pela Faculdade Cásper Líbero (SP). E-mail: deysicioccari@gmail.com.

- Vanderlei de Castro Exequiel é Doutorando em Ciências Sociais pela Universidade Estadual Paulista "Julio de Mesquita Filho". Atualmente é Membro do grupo de pesquisa Comunicação e Sociedade do Espetáculo do Programa de Pós-graduação da Faculdade Cásper Líbero. E-mail: vanderlei.ezequiel@unesp.br.

- Romer Mottinha Santos é Mestre em Ciência Política, pela Universidade Federal do Paraná. Atualmente é Pesquisador do Centro Universitário Internacional Uninter do Paraná. E-mail: romermottinha@gmail.com.

\section{Referências}

BAUMAN, Zygmunt. Vida Líquida. Rio de Janeiro: Jorge Zahar, 2007.

BOURDIEU, Pierre. Sobre a televisão. Rio de Janeiro: Jorge Zahar Ed., 1997.

BUCCI, Eugenio. Sobre Ética e Imprensa. Companhia das Letras. Guarujá, SP: Editora Companhia das Letras. 2004.

CIOCCARI, Deysi. O atentado contra Jair Bolsonaro: imagem e a violência nas eleições 2018. Líbero, 
Deysi Cioccari, Vanderlei Ezequiel e Romer Mottinha

ano XXI, $\quad$ n. 42, jul./dez. 2018. Disponível em: <http://seer.casperlibero.edu.br/index.php/libero/article/download/1009/937>. Acesso em: 11 ago. 2019.

CIOCCARI, Deysi; PERSICHETTI, Simonetta. Armas, ódio, medo e espetáculo em Jair Bolsonaro. Revista Alterjor, v. 18, n. 2, p. 201-214, 2018a. Disponível em: <http://www.revistas.usp.br/alterjor/article/view/144688>. Acesso em: 21 nov. 2019.

CIOCCARI, Deysi; PERSICHETTI, Simonetta. A política e o espetáculo em Jair Bolsonaro, João Doria e Nelson Marchezan. Revista Alterjor, v. 18, n. 2, p. 177-200, 2018b. Disponível em: <http://www.revistas.usp.br/alterjor/article/view/147321>. Acesso em: 21 nov. 2019.

DIAZ, Alvaro Paul. La penalización de la incitación al odio a la luz de la jurisprudencia comparada. Revista Chilena de Derecho, v. 38, n. 2, p. 503-609. 2011.

DWORKIN, Ronald. Foreword. In: HARE, Ivan; WEINSTEIN, James (Orgs.). Extreme speech and democracy. Nova York: Oxford University Press, 2009.

GARGARELLA, Roberto. Constitucionalismo y libertad de expresión. In: ORDOÑEZ, Maria Paz Ávila; SANTAMARÍA, Ramiro Ávila; GERMANO, Ramiro Gómez. Libertad de expresión: debates, alcances y nueva agenda. Quito, Ecuador: Organización de las Naciones Unidas para la Educación, la Ciencia y la Cultura, 2011.

HOBBES, Thomas. Leviatã ou matéria, forma e poder de um estado eclesiástico e civil. Tradução de João Paulo Monteiro e Maria Nizza Silva. São Paulo: Martins Fontes, 2003.

. Do cidadão. Tradução de Renato Janine Ribeiro. São Paulo: Martins Fontes, 1998.

The elements of law natural \& politic. Edited with a preface and critical notes by Ferdinand Tönnies. London: Frank Cass \& Co, 1969.

De corpore. In: HOBBES, Thomas. The english works of Thomas Hobbes. Tradução de W. Molesworth. London: Scientia Verlag Aalen, 1966. vol. I.

JAWORSKI Roberta. Bolsonaro é atacado a faca e operado de emergência; rivais condenam atentado. Folha de S. Paulo, 7 set. 2018.

LASCH, Cristopher. O mínimo eu. São Paulo, Brasiliense, 1986.

MEYER-PFLUG, Samantha Ribeiro. Liberdade de expressão e discurso do ódio. São Paulo: Editora Revista dos Tribunais, 2009.

MILL, John Stuart. On Liberty. In: MILL, John Stuart. American State Papers: the federalist. Chicago: Encyclopaedia Britannica Inc., 1978. p. 267-323.

REDETV. Superpop [Entrevista]. São Paulo: RedeTV, 2014. Programa de TV.

RIBEIRO, Renato Janine. Thomas Hobbes, ou: a paz contra o clero. In: BORON, Atilio A. Filosofia politica moderna. De Hobbes a Marx. Buenos Aires: CLACSO, 2006.

RILA, Luiz; KRIEGER, Gustavo. A última crise do governo. Ofendido com reportagem, Lula expulsa jornalista americano do Brasil e aceita retratação fajuta. Época, 17 maio 2004. Disponível em: <http://revistaepoca.globo.com/Epoca/0,6993,EPT728369-1653,00.html>. Acesso em: 21 nov. 2019.

RIOS, Roger Raup. Direito da antidiscriminação: discriminação direta, discriminação indireta e açoes afirmativas. Porto Alegre: Livraria do Advogado Editora, 2008.

SARMENTO, Daniel. A liberdade de expressão e o problema do hate speech. 2006. Disponível em: $<$ https://www.yumpu.com/pt/document/view/12839939/a-liberdade-de-expressao-eo- -problemado-hate-daniel-sarmento $>$. Acesso em: 11 jul. 2019. 
SCHMITT, Carl. O Conceito do Político. Tradução de Álvaro L. M. Valls. Petrópolis: Ed. Vozes, 1992.

SILVA, Rosane Leal da et al. Discurso do ódio em redes sociais: jurisprudência brasileira. Rev. direito GV, São Paulo, v. 7, n. 2, p. 445-467, jul./dez. 2011.

TEIXEIRA, Daniel. Pixuleco. Bolsonaro chuta boneco do ex-presidente Lula durante evento em Ceilândia (DF). Estado de S. Paulo, 1 set. 2018.

WALDRON, Jeremy. The harm in hate speech. Cambridge: Harvard University Press, 2012.

Texto recebido em 14 de agosto de 2019. Aprovado em 28 de outubro de 2019. 